\title{
Revealing full chemical forms of lead in wine with combined XRF-NMR technologies
}

\author{
J.E. Herbert-Pucheta ${ }^{1}$, Q.U. Ortega ${ }^{2}$, L.G. Zepeda-Vallejo ${ }^{3}$, D. Milmo-Brittingham ${ }^{4}$, G.P. Maya ${ }^{4}$, L.A.O. Aragón ${ }^{5}$, \\ E. Castillo ${ }^{6}$, F.R. González ${ }^{7}$, C. Pino-Villar ${ }^{8}$, and R.G. García ${ }^{9}$ \\ ${ }^{1}$ Consejo Nacional de Ciencia y Tecnología-Laboratorio Nacional de Investigación y Servicio Agroalimentario y Forestal. \\ Universidad Autónoma Chapingo. Carretera México-Texcoco Km 38.5, C.P. 56230, Chapingo, Estado de México, Mexico \\ ${ }^{2}$ Dirección de Insumos para la Producción - Secretaría Administrativa del Fondo Sectorial CONACyT - SAGAPRA. Secretaría \\ de Agricultura, Ganadería Desarrollo Rural, Pesca y Alimentación. Municipio Libre 377, piso 10 "A”, Col. Santa Cruz Atoyac, \\ C.P, 03310, Ciudad de México, Mexico \\ ${ }^{3}$ Departamento de Química Orgánica, Escuela Nacional de Ciencias Biológicas, Instituto Politécnico Nacional. Prolongación de Carpio \\ y Plan de Ayala s/n, Colonia Santo Tomás, 11340 Ciudad de México. Mexico \\ ${ }^{4}$ Consejo Mexicano Vitivinícola A.C. Montecito No 38 Piso 15 Despacho 22 - WTC México, C.P. 03810, Ciudad de México, Mexico \\ ${ }^{5}$ Laboratorio Nacional de Investigación y Servicio Agroalimentario y Forestal. Universidad Autónoma Chapingo. \\ Carretera México-Texcoco Km 38.5, C.P. 56230, Chapingo, Estado de México, Mexico \\ ${ }^{6}$ Laboratorio de Análisis Químicos, Instituto Mexicano del Petróleo. Eje Central Lázaro Cárdenas Norte 152, \\ Col. San Bartolo Atepehuacan, Delegación Gustavo A. Madero, C.P. 07730 Ciudad de México, Mexico \\ ${ }^{7}$ Casa Madero. Carretera Paila 102- Parras Km. 18.2; Hacienda San Lorenzo. Parras de la Fuente. C.P. 27980, Coahuila, Mexico \\ ${ }^{8}$ Monte Xanic. Lago Tangañica No. 18, Colonia Granada, Municipio Miguel Hidalgo, CP 11520, Ciudad de México, Mexico \\ ${ }^{9}$ Consejo Viticultores del Estado de Aguascalientes. Merlo 4, Quintas de Monticello, Jesús María, Aguascalientes. CP 20908, Mexico
}

\begin{abstract}
Since 1953, The World Organization of Vine and Wine (OIV) Member States have reduced the lead maximum limits (ML) in wines, down to $0.05 \mathrm{mg} / \mathrm{L}$ (2018). Evidently, this ML value is too restrictive for wine industry as it excludes from international market a significant portion of wine production. Currently, the Codex Committee on Contaminants in Foods and OIV had recognized the value of gathering robust and novel data to better assess the best lowest ML for wine industry. Currently, there is not a direct statement within international reference documents, of which chemical form of lead must be controlled and/ or reduced. This work presents for the first time a method combining Energy Dispersive X-Ray analysis (EDAX) and Nuclear Magnetic Resonance (NMR) spectroscopies in order to determine presence and concentrations of major and trace elements of lead and other element moieties in wine that can allow to better redefine lead's ML. By identification of $\mathrm{K}, \mathrm{L}, \mathrm{M}$, radiation shells with additional $\alpha \beta i$ labelling of lead's major and minor components with semi-quantitative XRF, combined with chemical-shift analysis of inorganic $\mathrm{Pb}^{4+}, \mathrm{Pb}^{2+}$ and/or organolead within wine samples, we propose a full discrimination framework to disentangle and quantify different chemical forms of lead.
\end{abstract}

\section{Introduction}

The concentration of metals in many alcoholic beverages can be a significant parameter to affect consumption and stock. For instance, OIV maximum lead limits (ML) in wines over the time have been controlled as follows: $0.6 \mathrm{mg} / \mathrm{L}$ (1953); $0.5 \mathrm{mg} / \mathrm{L}$ (1975); $0.3 \mathrm{mg} / \mathrm{mL}$ (1987); $0.25 \mathrm{mg} / \mathrm{mL}(1993) ; 0.2 \mathrm{mg} / \mathrm{L}(1996)$ and $0.15 \mathrm{mg} / \mathrm{mL}$ (2006) [1]. Some of the main sources of lead contamination in agriculture comprises an environmental source coming from factories, mining or the presence of lead in gasoleum; soil, metallic materials used in different wine production processes (raw materials, brewing, bottling, aging/ storage, adulteration) or the use of $\mathrm{Pb}_{3}\left(\mathrm{AsO}_{4}\right)_{2}$ pesticides [2]. At 2011, the Joint Food and Agriculture Organization (FAO) and World Health Organization (WHO) Expert Committee on Food Additives (JEFCA) has presented toxicological data of lead against human health, enhancing neurodevelopmental effects, renal dysfunctions, impaired fertility or hypertension, between others. Both JEFCA and the Codex Committee on Contaminants in Foods (CCCF) has established a prioritization to constantly measure lead's ML mostly in societies with prolonged dietary exposures to important levels of lead, in order to identify major contributing sources.

Recent studies have revealed that grapes' pectic polysaccharide "Rhamnogalacturonan-II (dRGII)" not degraded during vinificationis is able to form stable complexes with lead [3]. Furthermore, it has been demonstrated that (dRGII $)_{2}$ dimer increases lead accumulation in rats and failed to induce any significant excretion of faecal or urinary lead due to the extreme stable complex dRGII$\mathrm{Pb}$ - dRGII [4].

Lead is commonly present not only in wine with relative concentrations around or even above $1.2 \mathrm{mg} / \mathrm{L}$ 
[1,5-7], but also its presence have been reported in beer (around $0.25 \mathrm{mg} / \mathrm{L}$, [8]), brandy (around $0.25 \mathrm{mg} / \mathrm{L}$, [9]), cachaza (around $0.42 \mathrm{mg} / \mathrm{L},[7,9]$ ) or Scotch whisky (around $0.2 \mathrm{mg} / \mathrm{L},[10]$ ), amongst others beverages.

Often, atomic absorption spectrometry (AAS), atomic emission spectrometry (AES), inductively couples plasma mass spectrometry (ICP-MS) and inductively coupled plasma optical emission spectrometry (ICP-OES) are the standard analytical methods used for determination of major $(\mathrm{Na}, \mathrm{Mg}, \mathrm{P}, \mathrm{K}, \mathrm{Ca})$, minor and trace elements (Al, Cr, Mn, Fe, Co, Ni, Cu, Zn, As, Se, Sr, Cd, Ba and $\mathrm{Pb}$ ) in wines [11] and generally in foods due to their high detection power, high selectivity and sensitivity. However, determination of the total concentration of a metal in a given beverage as the most common characterization practice, but not their chemical form within the complex beverage matrix, does not adequately characterizes their positive or negative effects. As a result, metal speciation (process to yield evidence of the atomic of molecular form of the analyte) has gained importance. For instance bioavailability speciation of metals in beverages is usually more important than quantifications of metals' total concentrations themselves. As stated before, metal complexes are normally more toxic as they are better absorbed by organisms [12].

The need of alternative analytical methods to characterize metal speciation in wines becomes critical to provide information that can help to regulate $\mathrm{ML}$ of wine minerals. Nuclear Magnetic Resonance (NMR) spectroscopy has recently been accepted within OIV chair as a primary method to characterize the complex wine matrix in terms of targeted and non-targeted metabolomics strategies by combination of high-resolution proton $\left({ }^{1} \mathrm{H}\right)$ NMR meta-data and Multivariate Statistical Analysis (MSA) [13,14] in order to get discriminations between geographical origins, year of vintages, AOC, possible adulterations etc. in wines by differences of their metabolomics fingerprints. NMR spectroscopy has the advantage that almost all elements present an active spin for characterization in the liquid or in the solid state, of local chemical environments related in turn to speciation, in most of the cases with minimal sample preparation. Lead $(\mathrm{Pb})$ presents an active nuclei $\left({ }^{207} \mathrm{~Pb}\right)$ with spin quantum number $1 / 2$. In liquid state NMR it has been used to study organo-lead compounds, whereas in solidstate $\mathrm{NMR}, \mathrm{Pb}\left(\mathrm{NO}_{3}\right)_{2}$ is commonly used as an "NMR thermometer" for spectrometer temperature calibration [15], but to the best of our knowledge, the combination of liquid- and solid-state ${ }^{207} \mathrm{~Pb}$ NMR spectroscopy applied to lead speciation in wines has not been carried out until now. Lead-NMR spectroscopy for general food stuff analysis present three major challenges: 1) Low solubility of lead minerals in only slight acidic water solutions; 2$)$ the keen temperature dependence of ${ }^{207} \mathrm{~Pb}$ NMR signals (0.75$0.9 \mathrm{ppm} \mathrm{K}^{-1}$ ) and 3) the extremely large chemical shift range (11500 ppm). Scan of a ${ }^{207} \mathrm{~Pb}$ NMR signal within a chemical range between +6000 to $-5000 \mathrm{ppm}$ could be a tedious process if users work at inappropriate temperature or solubility conditions when being in the liquid-state. However, once controlled said limitations, metal speciation could be done in the liquid- or solid- state as lead different chemical forms present important chemical shift differences: $\mathrm{Pb}(\mathrm{IV})$ normally appear around $+5000 \mathrm{ppm}$, $\mathrm{Pb}$ (II) present a chemical shift dispersion between +3000

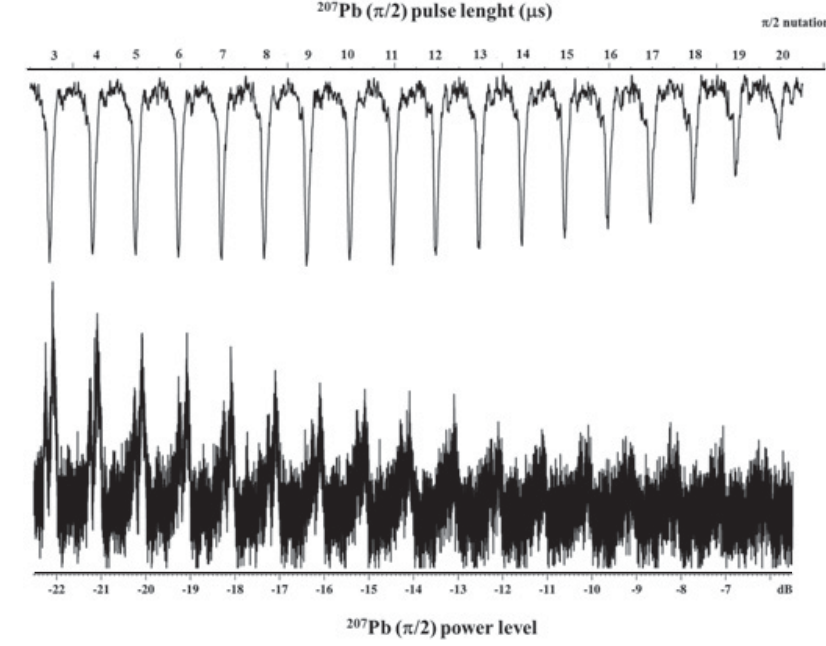

Figure 1. ${ }^{207} \mathrm{~Pb}$ liquid-state NMR spectra calibrations of 90 degree pulse power level (bottom, expressed in power level attenuation or $\mathrm{dB}$ ) and pulse length (top, expressed in microseconds) at a particular carrier frequency of $\mathrm{O} 1=$ $-3000 \mathrm{ppm}(-376686 \mathrm{~Hz})$ and spectral width $\mathrm{SW}=2995.5 \mathrm{ppm}$ $(0.375 \mathrm{MHz})$ of the standard lead citrate sample $\left(\mathrm{C}_{12} \mathrm{H}_{10} \mathrm{O}_{14} \mathrm{~Pb}_{3}\right)$.

and $-6000 \mathrm{ppm}$, whilst organo leads could appear between +500 and $-3000 \mathrm{ppm}$, when spectra are referenced to a standard $\mathrm{Me}_{4} \mathrm{~Pb}$ sample (0 ppm) [16,17].

Finally, X-Ray Fluorescence is a semi-quantitative emission spectroscopy (Energy Dispersive X-ray Spectroscopy, EDS) used to quantify chemical composition of samples by the use of an electron or X-Ray beam that ionize atoms at the level of the core electronic shells. Electrons from outer electronic shells fill the internal "holes" provoked by ionization, causing though the emission of X-Ray fluorescence lines. For instance if the initial vacancy occurs in the $\mathrm{K}$ shell (most internal shell), and the vacancy is filled by electrons from the adjacent shell ( $\mathrm{L}$ shell), a K $\alpha \mathrm{X}$-Ray is emitted. If vacancy is filled from electrons coming from further shells $(M$ shell), the emitted X-Ray is called as $\mathrm{K} \beta . \mathrm{L} \alpha$ and $\mathrm{L} \beta$ emitted radiation will correspond to electrons from $M$ shell filling the vacancy of ionized electrons from L shell.

The present work comprises the following steps: 1) Instrument calibration for NMR and XRF spectroscopy with known standards: $\mathrm{C}_{12} \mathrm{H}_{10} \mathrm{O}_{14} \mathrm{~Pb}_{3}$ and $\mathrm{Pb}\left(\mathrm{NO}_{3}\right)_{2}$. For NMR studies both liquid- and solid-state regimes were analysed, whilst for XRF, all experiments were done at the solid-state. First, NMR calibrations comprise $\pi / 2$ nutation frequencies and relaxation delays of lead standards at an imposed spectral width and carrier frequencies able to excite an appropriate broad bandwidth (Fig. 1). For liquidstate NMR spectroscopy, all calibrations were affected by the fast spin-spin relaxation times of lead-samples with low solubility in acidic water $(\mathrm{pH}=3.1)$. For XRF - EDAX spectroscopy, calibrations comprise electronic beam acceleration voltages, as well as number of counts (scan rate). 2) Scan of ${ }^{207} \mathrm{~Pb}$ NMR signal within a full chemical-shift range $(+6000$ to $-5000 \mathrm{ppm})$ at optimized $90^{\circ}$ pulses and relaxation delays. 3) Variabletemperature liquid-state ${ }^{207} \mathrm{~Pb}$ NMR spectroscopy of standards to retrieve maximal signal to noise ratio, as a function of temperature and 3) Measurements of lead traces in wine (liquid-state NMR) and grape must 
(solid-state NMR/XRF) at optimized spectroscopic and temperature conditions.

\section{Materials and methods}

\subsection{Lead standards}

Lead sample standards: lead citrate dimer $\left(\mathrm{C}_{12} \mathrm{H}_{10} \mathrm{O}_{14} \mathrm{~Pb}_{3}\right)$ and lead nitrate $\left(\mathrm{Pb}\left(\mathrm{NO}_{3}\right)_{2}\right)$ were prepared as follows: a) Liquid-state NMR spectroscopy. $5 \mathrm{mg}$ of lead solid standards were dissolved in $2 \mathrm{~mL}$ solution comprising $90 \%$ deionized $\mathrm{H}_{2} \mathrm{O}$ with a phosphonate buffer $\mathrm{KH}_{2} \mathrm{PO}_{4}$ $\left(0.1 \%\right.$, with respect the non-deuterated volume) and $\mathrm{NaN}_{3}$ ( $2 \%$, with respect the non-deuterated volume), and $10 \%$ of $\mathrm{D}_{2} \mathrm{O}$ (with respect the total volume), whereas $\mathrm{pH}$ was adjusted to a value of 3.1 , an acidic value that allow partial solubilisation of lead standards. b) Solid-state NMR spectroscopy. Approximately $100 \mathrm{mg}$ of $\mathrm{C}_{12} \mathrm{H}_{10} \mathrm{O}_{14} \mathrm{~Pb}_{3}$ solid sample was packed in a $4 \mathrm{~mm}$ rotor. c) XRF spectroscopy: Approximately $5 \mathrm{mg}$ of $\mathrm{C}_{12} \mathrm{H}_{10} \mathrm{O}_{14} \mathrm{~Pb}_{3}$ and $\mathrm{Pb}\left(\mathrm{NO}_{3}\right)_{2}$ were directly mounted within a $12 \mathrm{~mm}$ Diameter Carbon tape (Agar Scientific ${ }^{\mathrm{TM}}$ ).

\subsection{Wine samples}

Mexican wines of the Llano Colorado, San Vicente, Valle de Guadalupe, Baja California, México, presenting differences in terms of grape varieties and year of vintage were analysed for the present study, and hereafter identified as follows: Ancon San Vicente- Gran Reserva (AGR, year of vintage 2009, Nebbiolo + Caubernet Sauvignon); J2:10 - Reserva (J210, year of vintage 2014, Nebbiolo + Caubernet Sauvignon); Merlot 2016 (M16, year of vintage 2016, Merlot); Merlot 2017 (M17, year of vintage 2017, Merlot); Nebbiolo 2016 (N16, year of vintage 2016, Nebbiolo) and Nebbiolo 2017 (N17, year of vintage 2017, Nebbiolo). Sample preparation for NMR studies comprised the addition of $100 \mathrm{uL}$ of a mixture of $\mathrm{D}_{2} \mathrm{O}$ and chemical-shift reference sodium 3-(trimethylsilyl)-propionate-2, 2, 3, 3-d 4 (TSP), phosphonate buffer $\mathrm{KH}_{2} \mathrm{PO}_{4} \quad 0.1 \%$ and $2 \% \mathrm{NaN}_{3}$ to $900 \mu \mathrm{L}$ of wine sample, whereas $\mathrm{pH}$ was finally adjusted to a value of 3.1 for all samples. Samples were finally versed in standard $5 \mathrm{~mm}$ NMR tubes.

\subsection{Grape must sample}

$600 \mathrm{~g}$ of freshly crushed fruit juice containing grape skin, seed and stems coming from a Merlot 2018 variety (Cava 57, FW36+VW San Gil, Querétaro Mexico) were frozen down to $-80^{\circ} \mathrm{C}$ during one hour, prior to a three-day lyophilisation dehydration. The residual dried must was manually crushed until having a fine dust. Approximately $100 \mathrm{mg}$ of lyophilised must was packed in a $4 \mathrm{~mm}$ solidstate NMR rotor. As for lead standards, approximately $5 \mathrm{mg}$ of Merlot 2018 lyophilised grape must was directly mounted within a $12 \mathrm{~mm}$ diameter carbon tape for XRF analysis.

\subsection{Nuclear Magnetic Resonance (NMR) spectroscopy}

All liquid-state NMR spectra were recorded on a Bruker 600 AVANCE III HD equipped with a $5 \mathrm{~mm}{ }^{1} \mathrm{H} / \mathrm{D}$ BBO double resonance Smart Probe-head with z-gradient. As

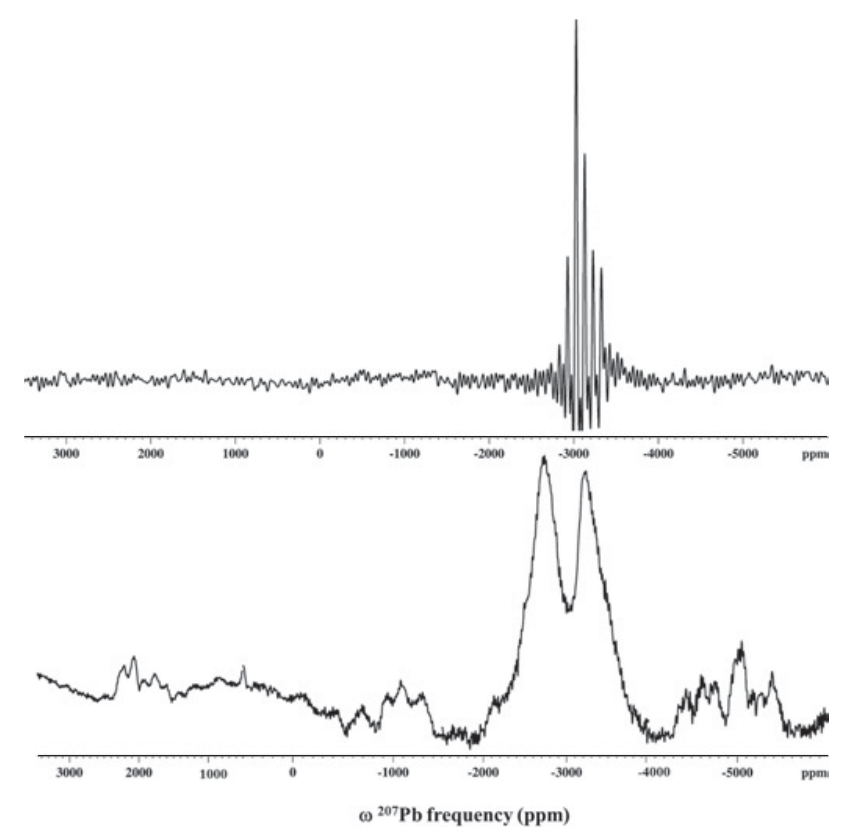

Figure 2. One dimensional optimized ${ }^{207} \mathrm{~Pb}$ NMR spectra in the solid (top) and liquid (bottom) state of lead citrate dimer $\mathrm{C}_{12} \mathrm{H}_{10} \mathrm{O}_{14} \mathrm{~Pb}_{3}$ used as reference for chemical shift and temperature calibrations. Both experiments were carried out at $25^{\circ} \mathrm{C}$.

the probe-head is limited to only ${ }^{1} \mathrm{H}-\mathrm{X}$ double resonance experiments, a matching and tuning calibration procedure to retrieve ${ }^{207} \mathrm{~Pb}$ frequency (125.55 MHz @ 14.095 Tesla) with respect the standard ${ }^{13} \mathrm{C}$ frequency $(150.93 \mathrm{MHz}$ @ 14.095 Tesla) was a compulsory step, prior to any experiment. All $1 \mathrm{D}^{2}{ }^{207} \mathrm{~Pb}$ NMR experiments were carried out at the following optimized conditions: lead direct excitation (zg) without ${ }^{1} \mathrm{H}$ decoupling with a hard $90^{\circ}$ pulse of 10 us@158 Watt of power level (Fig. 1), a carrier frequency $(\mathrm{O} 1)$ of $-376687 \mathrm{~Hz}$ and a spectral width (SW) of $375000 \mathrm{~Hz}$ were imposed for acquisitions, with accumulations of $4 \mathrm{~K}$ transients, collected into 4588 complex data points and acquisition times of 6 milliseconds with relaxation delays of 2 seconds, total experimental times per spectrum were of $2 \mathrm{~h} 19^{\prime}$. All solid-state ${ }^{207} \mathrm{~Pb}$ NMR spectra were recorded at $9.4 \mathrm{~T}$ $\left(400.13 \mathrm{MHz}\right.$ for ${ }^{1} \mathrm{H}$ frequency, $100.61 \mathrm{MHz}$ for ${ }^{13} \mathrm{C}$ frequency and $62.78 \mathrm{MHz}$ for ${ }^{207} \mathrm{~Pb}$ frequency) with a standard Bruker Avance I $4 \mathrm{~mm}$ Double Resonance MAS probe, at spinning frequencies of $8 \mathrm{kHz}$ MAS with direct excitation schemes, and no ${ }^{1} \mathrm{H}$ heteronuclear dipolar decoupling (Figs. 2 top and 7). With similar carrier frequency with respect the liquid-state NMR spectra $(\mathrm{O} 1=-376687 \mathrm{~Hz})$, experiments at the solid-state were developed with a spectral width of $11946 \mathrm{ppm}(1 \mathrm{MHz})$ and using an ADC spectra digitizer type, a broadband excitation profile was achieved with ${ }^{207} \mathrm{~Pb} 90$ degree pulses of 4 us. By having acquisition times of $4 \mathrm{~ms}$ and relaxation delay times of 2 seconds, a sort of 8466 complex points were recorded with $4 \mathrm{~K}$ total transients, that produce in turn experimental times of $2 \mathrm{~h} 19^{\prime}$.

For variable temperature experiments, a Bruker Variable Temperature Unit (VTU) was used to control temperature variations in the range between 20, 25, 30, 45 


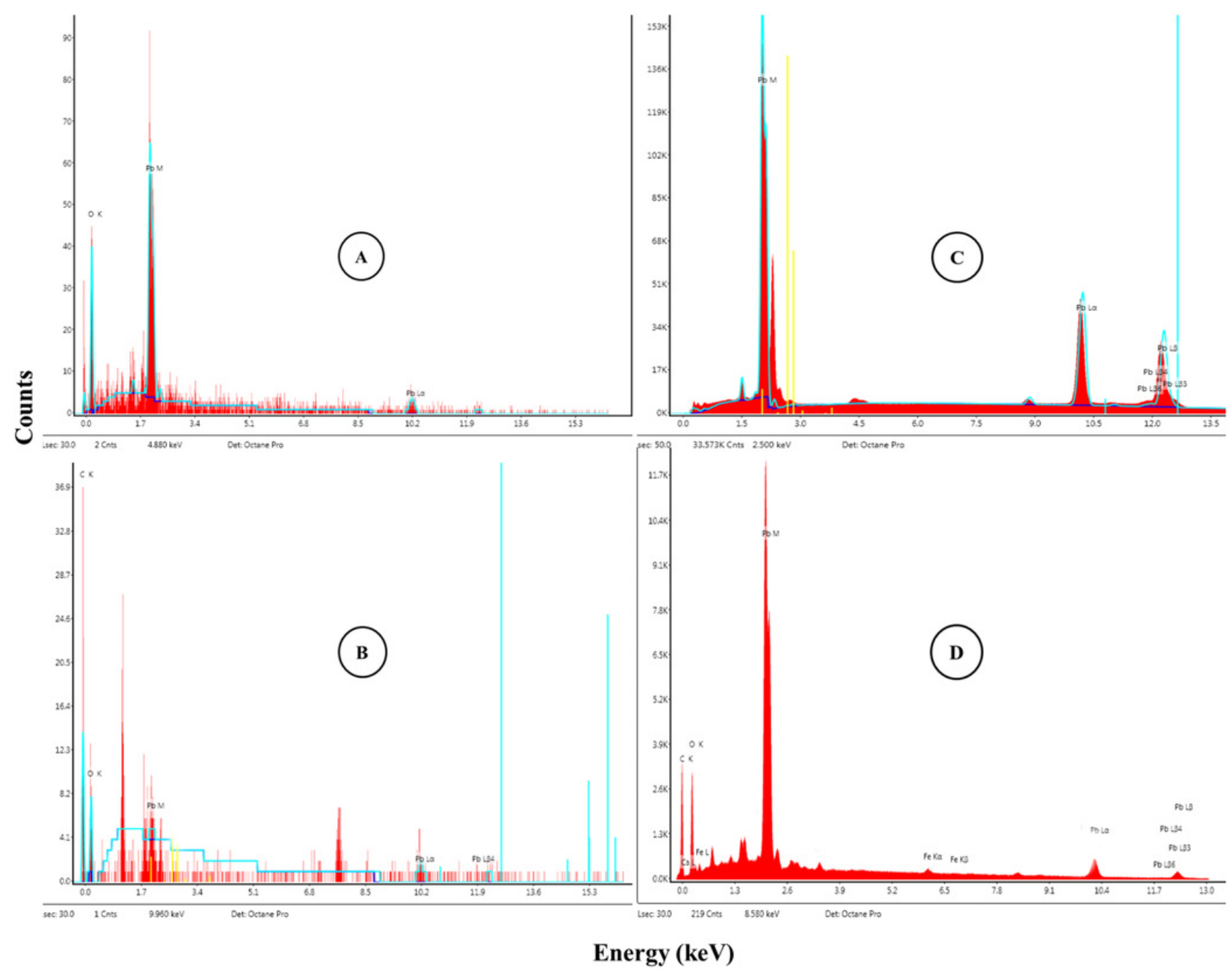

Figure 3. XRF-EDAX spectra of A) $\mathrm{Pb}\left(\mathrm{NO}_{3}\right)_{2}$ (90 counts), B) $\mathrm{C}_{12} \mathrm{H}_{10} \mathrm{O}_{14} \mathrm{~Pb}_{3}$ (40 counts), C) $\mathrm{Pb}\left(\mathrm{NO}_{3}\right)_{2}$ (153 K counts) and D) $\mathrm{C}_{12} \mathrm{H}_{10} \mathrm{O}_{14} \mathrm{~Pb}_{3}$ (12 K counts).

and $65^{\circ} \mathrm{C}$. Dry air was used for temperature variations. The flow rate was varied between 500 to $1070 \mathrm{~L} / \mathrm{h}$.

\subsection{XRF-EDAX emission spectroscopy profiles}

The X-Ray Fluorescence profiles were measured using a FEI-NOVA Scanning Electron Microscope (SEM) equipment, coupled with an EDAX module, applying a voltage of $30 \mathrm{kV}$ that produces an emission current of $83.8 \mathrm{uA}$. The dwell time was in all cases 30 us, in turn traduced to frame times of $28.6 \mathrm{~s}$. Electron beam was induced with a spot of 10 that produce in turn a resolution range of $1024 \times 884$. As stated above, sample preparation was performed by adhering all powders (standards and grape must) on a carbon tape without the requirement of any conductive coating deposition on the surface for EDAX analysis. Experimental times per XRF-EDAX profile were in the order of 2-5 minutes.

\section{Results and discussion}

The present work proposes a strategy to describe metal speciation of lead minor traces in wine and must in the liquid- and solid-state by combining semi-quantitative XRF-EDAX technology with ${ }^{207} \mathrm{~Pb}$ NMR spectroscopy. The approach intends not only to quantify lead minor traces as with conventional ICP schemes, but also to reveal the full chemical forms of lead that could be present since the must. However, several instrumental and chemical complications have to be taken into consideration prior to standardize the combined novel method. For instance, to retrieve a ${ }^{207} \mathrm{~Pb}$ NMR signal, regardless the state of the matter, it is compulsory to first tune and match the double resonance probe into the proper frequency $(125.55 \mathrm{MHz}$ @ 14.095 Tesla;), in instruments wherein conventional users shall compute ${ }^{13} \mathrm{C}$ NMR experiments $(150.93 \mathrm{MHz}$ @ 14.095 Tesla). For that, series of ${ }^{13} \mathrm{C}$ (Fig. 3) and ${ }^{207} \mathrm{~Pb}$ (Fig. 2, bottom) one-dimensional experiments of $\mathrm{C}_{12} \mathrm{H}_{10} \mathrm{O}_{14} \mathrm{~Pb}_{3}$ dimer were consecutively acquired within the same Smart probe in order to verify the accuracy of tuning and matching back and forth from $150.93 \mathrm{MHz}$ $\left({ }^{13} \mathrm{C}\right)$ to $125.55 \mathrm{MHz}\left({ }^{207} \mathrm{~Pb}\right)$ frequencies.

Second, retrieving a relevant lead NMR signal within its huge chemical shift range of $11500 \mathrm{ppm}$ could be done by having an optimized ${ }^{207} \mathrm{~Pb} 90$ degree pulse as prerequisite, wherein a broadband 90 degree pulse is defined as a short pulse-length with a proper power level, able to excite an important bandwidth. For that, Fig. 1 shows the optimization procedure for calibrating a ${ }^{207} \mathrm{~Pb} 90$ degree hard pulse able to excite a bandwidth of $3000 \mathrm{ppm}$ within the liquid-state. Similar treatment was done for the solid-state regime. Once an optimized 
hard pulse is obtained, a "signal hunting" is carried out at steps of $3000 \mathrm{ppm}$, by only switching the carrier frequency. Final result is depicted in Fig. 2, wherein $\mathrm{Pb}^{2+}$ signal from lead citrate dimer was observed between -3010 and $-3029 \mathrm{ppm}$. It is important to highlight that for solid-state ${ }^{207} \mathrm{~Pb}$ spectrum @ $8 \mathrm{kHz}$ MAS of $\mathrm{C}_{12} \mathrm{H}_{10} \mathrm{O}_{14} \mathrm{~Pb}_{3}$, spinning sidebands at $\mathrm{n} v_{\text {rot }}(n=1,2$, 3 ) are observed with respect the isotropic chemical shift of $-3029 \mathrm{ppm}$, whilst for the liquid-state regime, a broad doublet centred at $-3010 \mathrm{ppm}$ is present at $25^{\circ} \mathrm{C}$. Line broadening at both regimes is intrinsically present due to the fast $\mathrm{T}_{2}$ relaxation times that normally occur in solids and liquids with sample inhomogeneity (as poor solubility or heterogeneous mixtures) such as lead solutions in polar solvents. Furthermore it has been extensively reported the large chemical shift anisotropy and broad powder patterns that lead samples could have, that could be partially alleviated by the use of non-standard pulse sequence like for instance, the Wideband Uniform Rate Smooth Truncation Carr-Purcell-Meiboom-Gill (WURST - CPMG) schemes [18-20].

Said Ultra-Wideline techniques are out of the scope of the present study, as they are optimized to modulate anisotropic interactions present in the solid state at relatively smooth $\mathrm{T}_{2}$ relaxation rates. In contrast the present study comprises both liquid- and solid-state NMR analysis of lead samples and/or traces, immersed in aqueous environments that promote fast $T_{2}$ relaxation times of lead spins. Because of this unavoidable condition, it becomes imperative to control the rest of the spectroscopic and thermodynamics conditions (pulse calibrations at certain bandwidths and temperature) in order to characterize lead speciation by NMR in aqueous media.

Third step comprises the temperature calibration of lead standards for NMR lead speciation. It has been undertaken a Variable Temperature (VT) NMR investigation of the temperature dependence of lead standards $\mathrm{Pb}\left(\mathrm{NO}_{3}\right)_{2}$ and $\mathrm{C}_{12} \mathrm{H}_{10} \mathrm{O}_{14} \mathrm{~Pb}_{3}$ as it has been elsewhere reported that isotropic chemical shifts of lead samples are not only temperature dependent, but also sensitive to concentration and solvent [15]. Figure 5 presents the liquid-state NMR stacked plots of lead nitrate (left) and lead citrate dimer (right) at different temperatures ranging from $20^{\circ} \mathrm{C}$ to $65^{\circ} \mathrm{C}$. Maximal signal to noise ratio is unambiguously appreciated between $25-30{ }^{\circ} \mathrm{C}$. Interestingly, the doublet observed at $25^{\circ} \mathrm{C}$ in both Figs. 2 and 5 and for both standards, is collapsed at $30^{\circ} \mathrm{C}$. The last strongly suggest that a coalescence regime is active between said temperatures ranges, wherein at $25^{\circ} \mathrm{C}$ it is appreciated a possible two-site lead moiety, averaged with a better signal-to-noise ratio when sample is heated only five more degrees.

Figure 3 shows the orthogonality that XRF-EDAX spectra can provide to ${ }^{207} \mathrm{~Pb}$ NMR speciation. Lead standard samples $\mathrm{Pb}\left(\mathrm{NO}_{3}\right)_{2}$ [A: 90 counts, $\mathrm{C}: 153 \mathrm{~K}$ counts] and $\mathrm{C}_{12} \mathrm{H}_{10} \mathrm{O}_{14} \mathrm{~Pb}_{3}$ [B: 40 counts, D: $12 \mathrm{~K}$ counts] were analysed. Since few scan-rates (A and B), three characteristic emission signals are observed: $\mathrm{Pb}(\mathrm{M}) @ 1.8 \mathrm{keV} ; \mathrm{PbL} \alpha @ 10.2 \mathrm{keV}$ and PbL $\beta$ @12keV, being though a pattern refined at longer counts (Fig. 3C and $\mathrm{D})$. The last can be regarded as a $\mathrm{Pb}^{2+}$ XRF-EDAX fingerprint that will serve to characterize solid oenological relevant samples for lead speciation.

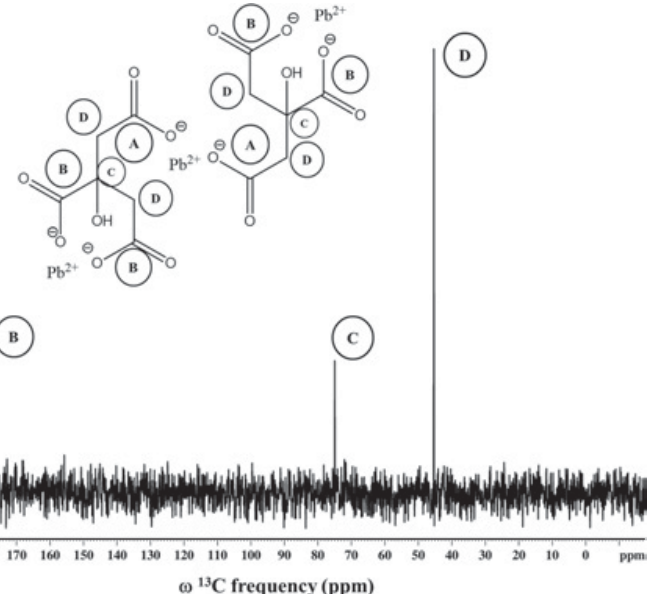

Figure 4. ${ }^{13} \mathrm{C}$ NMR spectrum of lead citrate dimer $\mathrm{C}_{12} \mathrm{H}_{10} \mathrm{O}_{14} \mathrm{~Pb}_{3}$ as a control parameter when switching from ${ }^{13} \mathrm{C}$ to ${ }^{207} \mathrm{~Pb}$ frequencies within a Double Resonance TXI probe (see Methods).

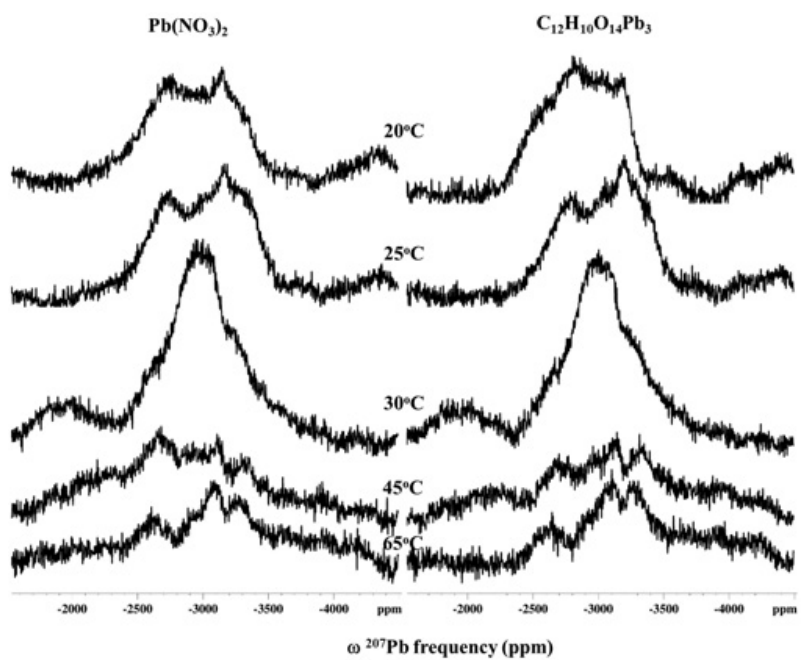

Figure 5. Variable temperature liquid-state one-dimensional ${ }^{207} \mathrm{~Pb}$ NMR spectra of $\mathrm{Pb}\left(\mathrm{NO}_{3}\right)_{2}$ (left) and $\mathrm{C}_{12} \mathrm{H}_{10} \mathrm{O}_{14} \mathrm{~Pb}_{3}$ (right) standard solutions.

Oenological samples in the liquid (wine) and solid (grape must) states were then characterized by the novel combined XRF-NMR method.

For liquid-state ${ }^{207} \mathrm{~Pb}-\mathrm{NMR}$ characterization of wine samples, series of different aged wine varieties were analysed with optimized NMR conditions at two different temperatures, shown in Fig. $6 .{ }^{207} \mathrm{~Pb} \mathrm{NMR}$ experiments were carried out at exactly the same acquisition conditions with respect the standards (see Materials and Methods). First, all wine samples AGR, J210, M16, M17, N16 and N17 present similar ${ }^{207} \mathrm{~Pb}-\mathrm{NMR}$ spectra at $25^{\circ} \mathrm{C}$ (broad doublet) and at $30^{\circ} \mathrm{C}$ (broad singlet) with respect $\mathrm{Pb}\left(\mathrm{NO}_{3}\right)_{2}$ and $\mathrm{C}_{12} \mathrm{H}_{10} \mathrm{O}_{14} \mathrm{~Pb}_{3}$ spectra (Fig. 5). Keen differences between wine and standard samples are in terms of signal integration: in all cases wine samples produce a roughly $10^{-3}$ less intense signal when compared to standards. Equivalency between line-shapes at a particular temperature between standards and wine samples, but differences in signal intensity might strongly suggest that any $\mathrm{Pb}^{2+}$ source dissolved at $\mathrm{pH}=3.1$, 


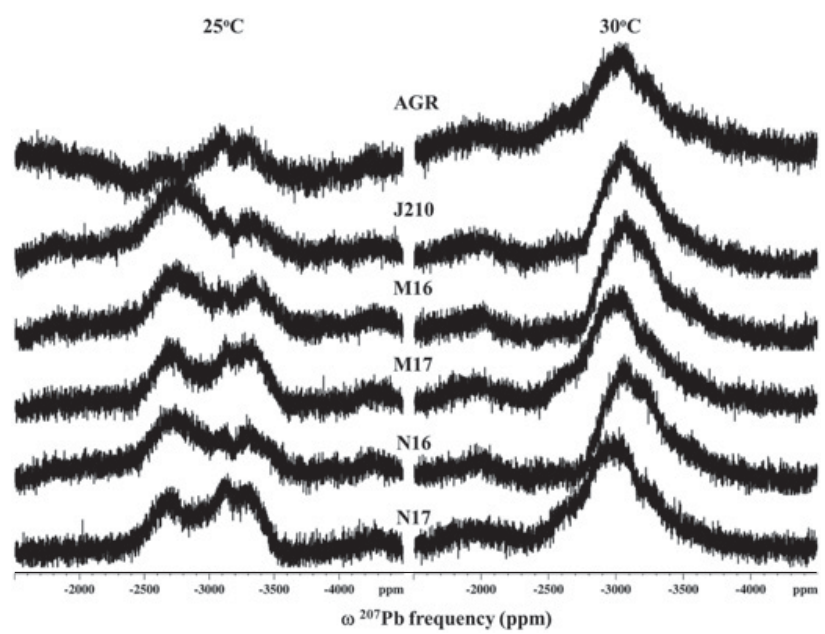

Figure 6. Variable temperature liquid-state one-dimensional ${ }^{207} \mathrm{~Pb}$ NMR spectra at $25^{\circ} \mathrm{C}$ (left) and $30^{\circ} \mathrm{C}$ (right) of AGR (2009), J210 (2014), M16 (2016), M17 (2017), N16 (2016) and N17 (2017) wine samples.

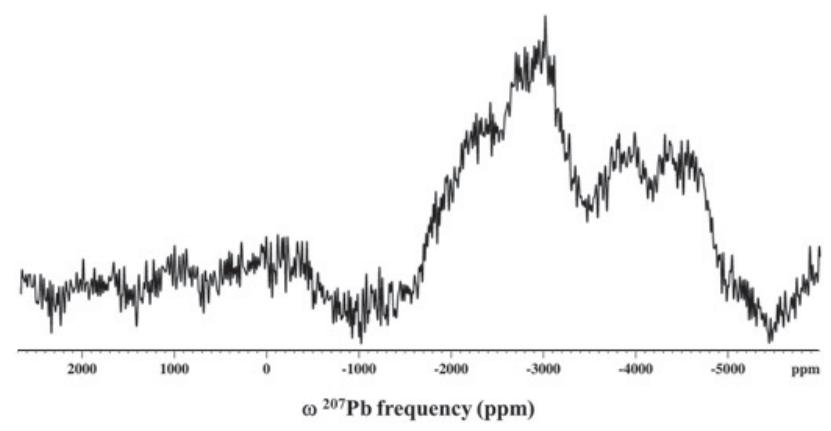

Figure 7. One-dimensional ${ }^{207} \mathrm{~Pb}$ solid-state NMR spectrum of 2018 Merlot lyophilised grape must carried out at $25^{\circ} \mathrm{C}$ and $8 \mathrm{kHz}$ MAS by direct excitation without ${ }^{1} \mathrm{H}$ heteronuclear dipolar decoupling.

will be chemically transformed into $\mathrm{PbCO}_{3}$ which is the most stable lead source in aqueous acidic media $\left(0.00011 \mathrm{~g} / 100 \mathrm{~mL} @ 20^{\circ} \mathrm{C}\right)$ [21]. Signal integration of wine ${ }^{207} \mathrm{~Pb}-\mathrm{NMR}$ spectra with respect standards indicate that relative concentration of lead $\mathrm{Pb}^{2+}$ source in wine samples would be in the order of 1.5 to $2.5 \mathrm{ppm}$, wherein metal speciation in wine is confirmed by chemical shift analysis. However, line-broadening effect due to fast $T_{2}$ relaxation will not precisely produce quantitative spectra. In this sense, acquisition of quantitative liquid-state ${ }^{207} \mathrm{~Pb}-$ NMR spectra of wine samples will be published elsewhere.

In contrast, ${ }^{207} \mathrm{~Pb}$ solid-state NMR spectrum of 2018 Merlot lyophilised grape must, shown in Fig. 7, shows a particular powder pattern of detected lead source. By chemical shift analysis it is confirmed the presence of a $\mathrm{Pb}^{2+}$ source and the absence of $\mathrm{Pb}^{4+}$ (i.e. not signal at around $+5000 \mathrm{ppm}$ ). However, when spectrum from Fig. 7 is compared with the lead standard spectrum of Fig. 2, the former presents a complex chemical shift anisotropy and/or the presence of more than one $\mathrm{Pb}^{2+}$ state. Line-shape analysis suggest that must's ${ }^{207} \mathrm{~Pb}$ solidstate NMR spectrum is defined by at least two $\mathrm{Pb}^{2+}$ states, each with a complex chemical shift anisotropy. Full characterization of chemical shift anisotropies of

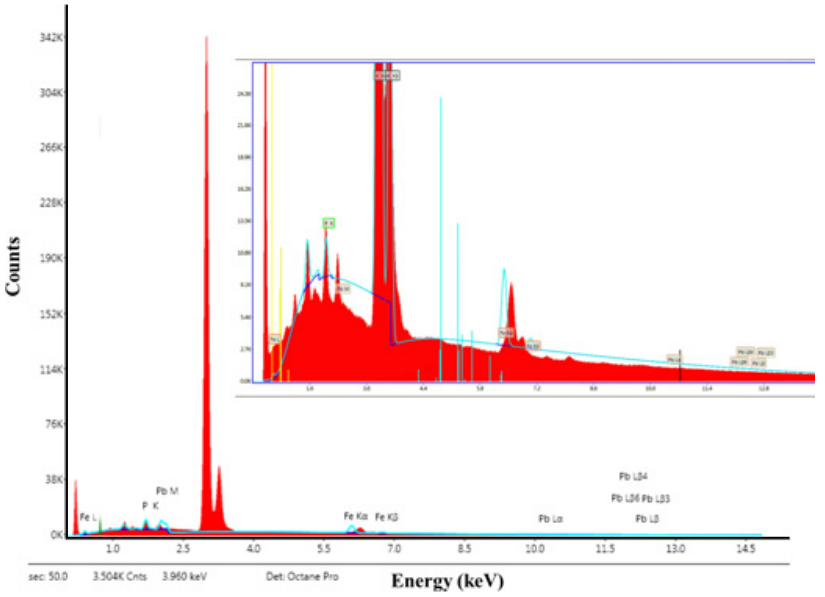

Figure 8. XRF-EDAX profile of a 2018 Merlot lyophilised grape must, acquired in similar conditions with respect standard (Fig. 2C).

lead moieties in must by ${ }^{207} \mathrm{~Pb}$ solid-state NMR at highspinning speeds $(>30 \mathrm{kHz})$ combined with ultra-wideline rotor synchronized techniques will be published elsewhere. For now, solid-state NMR of lead minor traces in grape must is presented for the first time to confirm the full chemical forms of $\mathrm{Pb}^{2+}$ in wine raw solid material. In this state of the matter, presence of lead minor traces is not penalized by the low solubility conditions needed to be accomplished in order to be present in the liquid state and though detection of lead in the solid-state becomes easier in terms of sensitivity, with respect its liquid-state NMR counterpart.

Finally a stock from the same 2018 Merlot lyophilised grape must was analysed by means of a XRFEDAX profile (Fig. 8). Beside detection of potassium, phosphorous and iron within the must, XRF reveals the presence of emission signals at $1.8 \mathrm{keV}(\mathrm{Pb}(\mathrm{M}))$; $10.2 \mathrm{keV}(\mathrm{PbL} \alpha)$ and $12 \mathrm{keV}(\mathrm{PbL} \beta)$, as characteristic pattern of minor traces of $\mathrm{Pb}^{2+}$ within the grape must at a concentration close to the limit of detection for higher energy emission signals.

\section{Conclusions}

For the first time to the best of our knowledge, we have designed a method combining XRF-NMR technologies to reveal metal speciation of lead in relevant oenological samples in both liquid- and solid-state regimes. First we have reported the way to tackle some of the intrinsic complications to compute ${ }^{207} \mathrm{~Pb}$ NMR spectra in aqueous media, mostly focused on the way to circumvent signal detection in large spectral widths, affected by concentration, temperature (coalescence effect) and $\mathrm{T}_{2}$ relaxation times that produce short life-time signals. By analysing lead with liquid-state NMR spectroscopy, we conclude by chemical-shift and line-shape analysis that $\mathrm{Pb}^{2+}$ in the way of $\mathrm{Pb}\left(\mathrm{CO}_{3}\right)_{2}$ is the most stable form of lead in wine liquid samples at $\mathrm{pH}=3.1$. In the other hand, ${ }^{207} \mathrm{~Pb}$ solid-state NMR studies suggest that at least two chemical forms of $\mathrm{Pb}^{2+}$ are present within the grape must and thus reinforces the hypothesis that lead source in wines are coming since vintage or before in a relative concentration of some ppm's. Full characterisation of $\mathrm{Pb}^{2+}$ 
states in the solid-state regime by high-resolution nonconventional NMR techniques are on their way in order to provide a full landscape for metal speciation, mostly to confirm the presence of organo-lead (II), which is highly toxic for human consumption. XRF-EDAX solidstate semi quantitative approach is used as a fast method for metal speciation and confirmation of presence of $\mathrm{Pb}^{2+}$ moieties in terms of specific emission signals so far not exploited. Finally, it is proposed to combine the present approach with classical absorption - emission spectroscopies to guaranty the quantification and metal speciation of lead forms in relevant oenological samples in order to contribute the reconsideration of maximum ML limits by specifying a particular toxic lead form needed to be controlled.

The present work was supported by the Mexican Ministry of Science and Technology (CONACyT), by means of the program "Cátedras CONACyT". We thank Mr. Alberto Curis Montesinos, commercial director of Vinícola Regional de Ensenada that provided all liquid state samples and M.Sc. Carlos Parrodi for providing grape must samples. We specially appreciate the assistance of M. Sc. Ernesto Ladrón de Guevara for preparing lyophilised grape must samples, as well for fruitful discussions. J.E.H.P. will like to specially acknowledge Dr. Virginia Jáuregui and Dr. David Vargas from Bruker Biospin for their assistance in NMR instrumentation, innovations, sales and management. A special acknowledgment to Ing. Edna Abigahil Ávalos Baez for her support in acquiring XRF-EDAX profiles of grape must.

\section{References}

[1] Code of Practice for the prevention and reduction of lead contamination in foods. Food and Agric. Org., CAC/RCP 56, 2004 (2004)

[2] P. Pohl, Trends Analyt. Chem. 26, 941 (2007)

[3] P. Pellerin, O’Neill, C. Pierre, M. T. Cabanis, A.G. Darvil, P. Albersheim, M. Moutounet, J. Int. Sci. Vigne Vin. 31, 33 (1997)

[4] M. Tahiri, P. Pellerin, J.C. Tressol, T. Doco, D. Pépin, Y. Rayssiguier, C. Coudray, J. Nutr. 130, 249 (2000)
[5] R. Bulinski, L. Wyszogrodzka-Koma, Z. Marzec, Bromatol. Chem. Toksykolo. (Poland) 28, 253 (1995)

[6] C.M. Mena, C. Cabrera, M.L. Lorenzo, M.C. Lopez, J. Agric. Food Chem. 45, 1812 (1997)

[7] E.H. Soufleros, A.S. Mygdalia, P. Natskoulis, Food Chem. 86, 625 (2004)

[8] C. Reilly, Ecol. Food Nutr. 2, 43 (1973)

[9] S.M. Bettin, W.D. Isique, D.W. Franco, M.L. Andersen, S. Knudsen, L.H. Skibsted, Euro. Food Res. Technol. 215, 169 (2002)

[10] T. Adam, E. Duthie, J. Feldmann, J. Inst. Brewing 108, 459 (2002)

[11] H. Eschnauer, L. Jakob, H. Meierer, R. Neeb, Mikrochim. Acta 99, 291 (1989); S. Frias, J.P. PérezTrujillo, E.M. Peña, J.E. Conde, Euro. Food Res. Technol. 213, 145 (2001); E. Orvini, M. Speziali, A. Salvani, C. Herborg, Microchem. J. 67, 97 (2000)

[12] A.M. Green, A.C. Clark, G.R. Scollary, Fresenius J. Anal. Chem. 358, 711 (1997)

[13] R. Godelman, F. Fang, E. Humpfer, B. Schütz, M. Bansbach, H. Schäfer, M. Spraul, J. Agric. Food Chem. 61, 5610 (2013)

[14] J.E. Herbert-Pucheta, I. Mejía Fonseca, L.G. ZepedaVallejo, D. Milmo-Brittingham, G.P. Maya, accepted OIV ref. 2018 (2018)

[15] G.M. Bernard, A. Goyal, M. Miskolzie, R. McKay, Q. Wu, R. E. Wasylishen, V.K. Michaelis, J. Magn. Reson. 283, 14 (2017)

[16] J.E.H. Buston, T.D.W. Claridge, R.G. Compton, M.G. Moloney, Magn. Reson. Chem. 36, 140 (1998)

[17] V. Sharma, S. Agarwal, R. Bohra, V.K. Jain, J. Chem. Res. 4, 273 (2004)

[18] L.A. O’Dell, A.J. Rossini, R.W. Schurko, Chem. Phys. Lett. 468, 330 (2009)

[19] L.A. O’Dell, R.W. Schurko, Chem. Phys. Lett. 464, 97 (2008)

[20] L.A. O’Dell, Solid State Nucl. Magn. 55-56, 28 (2013)

[21] NIH, United States National Library of Medicine, National Centre for Biotechnology Information, https://pubchem.ncbi.nlm.nih.gov/compound/ 11727 